\title{
Caracterização de atributos físico-químicos de um latossolo amarelo no Município de Paragominas - PA
}

Characterization of physical and chemical attributes of a yellow latosol in the Municipality of

Paragominas - PA

Caracterización de atributos físicos y químicos de un latosol amarillo en el Municipio de

Paragominas - PA

Recebido: 18/01/2021 | Revisado: 21/01/2021 | Aceito: 30/01/2021 | Publicado: 06/02/2021

Camila Nascimento Alves

ORCID: https://orcid.org/0000-0001-5093-7078 Universidade do Estado do Pará, Brasil

E-mail: camila.alves@uepa.br

Nayra de Lima Ferreira

ORCID: https://orcid.org/0000-0002-1858-6965 Universidade do Estado do Pará, Brasil

E-mail: nayralima1400@gmail.com

Gabriela Brito de Souza

ORCID: https://orcid.org/0000-0002-7976-5262 Universidade do Estado do Pará, Brasil E-mail: gabrielasouza.br99@gmail.com

Larissa Lopes Barroso

ORCID: https://orcid.org/0000-0001-9462-0435 Universidade do Estado do Pará, Brasil

E-mail: larissabarroso.amb18@gmail.com

Jafison Antônio Freires da Silva

ORCID: https://orcid.org/0000-0001-6873-8149 Universidade do Estado do Pará, Brasil

E-mail: jafisonfreires@gmail.com

Renato Braga Maciel Brito

ORCID: https://orcid.org/0000-0001-6109-9305 Universidade do Estado do Pará, Brasil E-mail: renatomaciel2096@gmail.com Edson Evanílson Pereira Melo

ORCID: https://orcid.org/0000-0003-2122-3433 Universidade do Estado do Pará, Brasil E-mail: edsonmelo145@gmail.com

\begin{abstract}
Resumo
A aptidão dos solos está diretamente relacionada às funções ambientais que são desempenhadas dentro de determinado ecossistema, seja ele natural ou de manejo. Diante dos impactos gerados através do uso inadequado do solo, o principal objetivo deste trabalho foi executar a caracterização físico-química de um latossolo amarelo localizado no município de Paragominas, região sudeste do estado do Pará, região Norte do Brasil como ferramenta para auxiliar nos estudos sobre qualidade dos solos. Realizou-se a coleta de amostras do referido solo em duas profundidades: $0-20 \mathrm{~cm}$ e de 20 $\mathrm{cm}-40 \mathrm{~cm}$, respectivamente. E a partir disso, executou-se análises laboratoriais, tais como, umidade natural, cor (Método de Munsell), mensuração do $\mathrm{pH}$, granulometria e teor de carbono orgânico. O método utilizado nesta pesquisa foi o quanti-qualitativo. Os resultados demonstraram que a cor da amostra indicou predominância vermelha (R), pH ácido. Em relação a granulometria, esta foi classificada como franco-argilosa, que também é conhecida como textura média, e, por fim, o carbono orgânico analisado indicou variações, que estão diretamente relacionadas a dificuldade de oxidação das amostras. Em suma, foi possível observar que os solos coletados nas duas profundidades indicaram baixa dissemelhança entre si, apresentando resultados pouco distintos apesar da mudança de horizonte.
\end{abstract}

Palavras-chave: Qualidade do solo; Amostragem; Parâmetros físico-químicos.

\section{Abstract}

Soil aptitude is directly related to the environmental functions that are performed within a given ecosystem, be it natural or management. In view of the impacts generated through inadequate use of the soil, the main objective of this work was to perform the physical-chemical characterization of a yellow latosol located in the municipality of Paragominas, in the southeastern region of the state of Pará, in the northern region of Brazil. Samples of the soil were collected at two 
depths: $0-20 \mathrm{~cm}$ and $20 \mathrm{~cm}-40 \mathrm{~cm}$, respectively. And from that, laboratory analyzes were performed, such as natural humidity, color (Munsell's method), $\mathrm{pH}$ measurement, particle size and organic carbon content. The method used in this research was quantitative and qualitative. The results showed that the color of the sample indicated a predominance of red $(\mathrm{R})$, acidic $\mathrm{pH}$. In terms of granulometry, it was classified as clay-loam, which is also known as medium texture, and, finally, the organic carbon analyzed indicated variations, which are directly related to the difficulty of oxidizing the samples. In summary, it was possible to observe that the soils collected at the two depths indicated low dissimilarity between them, presenting slightly different results despite the change in the horizon.

Keywords: Soil quality; Sampling; Physical-chemical parameters.

\section{Resumen}

La idoneidad de cualquier suelo está directamente relacionada con las funciones ambientales que desempeña dentro de un determinado ecosistema, ya sea natural o gestionado. Teniendo en cuenta los impactos generados por el uso incorrecto del suelo, el objetivo principal de este trabajo fue realizar un análisis de laboratorio de los atributos físicos y químicos de dos muestras de suelo recogidas en la región sureste del estado de Pará, específicamente en el municipio de Paragominas, región norte de Brasil. El método utilizado en esta investigación fue cuanti-cualitativo. A partir de ellos se realizaron análisis de laboratorio, como la humedad natural del suelo, el color de la muestra de suelo (comparación de horizontes), la medición del pH, el tamaño de las partículas y el contenido de carbono orgánico. En cuanto a los resultados, se observó que la humedad natural del suelo era de aproximadamente $5 \mathrm{~g}$ para ambas muestras, además, el color de la muestra indicaba un predominio del rojo (R) así como un pH ácido para ambas muestras. En cuanto a la granulometría, se clasificó como libre de arcilla, lo que también se conoce como textura media, y finalmente, el carbono orgánico analizado indicó variaciones, que están directamente relacionadas con la dificultad de oxidación de las muestras. En síntesis, con base en los conocimientos adquiridos, fue posible observar que el suelo de las muestras utilizadas para el análisis de laboratorio de los atributos fisicoquímicos indicó baja disimilitud entre ellas, presentando resultados poco distintos a pesar del cambio de horizonte.

Palabras clave: Calidad del suelo; Muestreo; Parámetros físico-químicos.

\section{Introdução}

A aptidão dos solos está diretamente relacionada às funções ambientais que desempenha dentro de determinado ecossistema, seja ele natural ou de manejo. Dentre essas funções pode-se destacar (1) a oferta de nutrientes para as mais variadas vegetações, (2) suporte para a habitação animal, (3) além de interferir na qualidade dos cursos hídricos. Deste modo, a condição do solo pode vir a impactar tanto de forma negativa quanto positiva ao meio ambiente, pois ele é essencial para que se detenha um equilíbrio relativamente sustentável (Cunha et al., 2012).

Devido as atividades realizadas pelo homem é notório que as alterações derivadas das variações de uso do solo estão sendo negativas e com altos impactos ao meio ambiente, tendo em vista que o uso do solo, especialmente para as atividades que proporcionam recursos financeiros, como é o caso da agricultura e pecuária influenciam diretamente na resiliência do solo, já que na maioria das vezes podem não retomar a sua forma original, seja pelo tipo superficial, ou das espécies que até então eram nativas nessas áreas (Carneiro et al., 2009).

Dentre os meios que podem mensurar a degradação do solo tem-se a análise das propriedades físicas e químicas. Em relação aos atributos químicos, eles são caracterizados pela diminuição dos teores originais de matéria orgânica e de importantes elementos minerais, a exemplo do ferro $(\mathrm{Fe})$ que é determinante para a coloração do solo. Em relação às propriedades físicas pode-se observar a mudança de textura face à sua originalidade (Queiroz, 2013).

Outrossim, um dos atributos físicos que se pode observar em solos degradados são a desestruturação e a compactação, já que devido as constantes aplicações de pressõesdevido ao tráfego de maquinários na agricultura, por exemplo, influenciam na textura, ciclos de umedecimento, secagem e densidade. Assim, o solo sofre um processo de empobrecimento de nutrientes, gerando interferência nos ciclos biogeoquímicos, em especial no ciclo do carbono (C), tornando as áreas mais propícias ao intemperismo dos solos. Além disso, uma das conseqüências da compactação nos solos se refere ao Acúmulo superficial de água e erosão hídrica, que pode ocasionar assoreamento dos mananciais (Müller et al.,2014). 
Diante dos impactos gerados através do uso inadequado do solo, o principal objetivo deste trabalho foi realizar a caracterização de atributos físico-químicos de um latossolo amarelo localizado no município de Paragominas, no estado do Pará, região norte do Brasil.

\section{Revisão Teórica}

O Índice de qualidade do solo (IQS) deve identificar um conjunto de propriedades e atender inúmeros critérios, tais como propriedades físicas e químicas do solo, elucidação de processos no ecossistema, propriedades biológicas, ser acessível a muitos usuários e utilizar técnicas replicáveis no campo e laboratório, além de possuir sensibilidade a mudanças climáticas, conforme Doran e Parkin (1994).

Dentre os impactos no solo a retirada da cobertura vegetal, principal responsável pela proteção desse recurso natural, desencadeia diversas problemáticas, dentros os quais tem-se o intemperisco que, posteriormente pode provocar a erosão e perda de nutrientes do solo. Além da problemática de elevado impacto ambiental/social, que são as alterações climáticas, especialmente no que se refere ao efeito estufa, já que a retirada da floresta implica na supressão de locais naturais do gás metano $\left(\mathrm{CH}_{4}\right)$, que são responsáveis pela remoção de aproximadamente $0,0004 \mathrm{t} \mathrm{ha}^{-1}$ desse gás do solo (Carvalho, 2014).

Guerra e Fullen (2016), afirmam que os fenômenos climáticos também são fatores a serem considerados como problemática para a qualidade do solo, tendo em vista que com a intensificação das precipitações nessas zonas, é possível constatar um terreno totalmente frágil e mal estabilizado. Logo, estará sujeito a ações erosivas, pois não tem a cobertura vegetal nativa para executar assistência contra a ação das gotículas de água que irão entrar em contato com o solo, existindo assim o designado efeito "Splash", que será a colisão intensificada da pluviosidade.

Arcoverde et al. (2015) em pesquisa sobrea qualidade física de solos para uso agrícola na região semiárida do estado da Bahia, concluíram que a ação antrópica, a exemplo do extrativismo para o uso agrícola, é um grande vilão nas alterações no perfil do solo. Os autores afirmam que a vegetação detentora de raízes profundas, não pode penetrar no solo com facilidade para conclusão do ciclo de crescimento, e como fauna e flora estão integradas entre si para manter o equilíbrio ecológico, é perceptível que se não houver germinação de sementes que servem de alimento para as mais variadas espécimes da fauna local, elas podem vir a sofrer extinção. Além disso, as atividades microbianas também são afetadas, já que não conseguirão realizar a ciclagem dos nutrientes e da matéria orgânica, para a fertilidade do solo.

Lopes e Albuquerque (2018) em estudo bibliográfico sobre o uso de agrotóxicos constataram que impactos são gerados pelo uso de fertilizantes e defensivos agrícolas, especialmente o Dicloro-Difenil-Tricloroetano (DDT) principal agente gerador das contaminações do solo e dos recursos hídricos, além de ser responsável pelo retardamento do estômato dos vegetais nas áreas de plantio, pois a aplicação de fertilizantes aliado ao uso de maquinários pesados, vem a gerar exaustão nesses terrenos.

De acordo com Torres (2015), em pesquisa efetuada no oeste do estado do Maranhão, até então não se obtinha informações acerca de estudos de reconhecimento e variações nas propriedades físico-químicas provocadas pelo sistema de manuseamento e utilização do solo. Portanto, estas análises são de suma relevância, uma vez que proporciona uma grande quantidade de informações em relação a um progresso no estudo físico-químico do solo.

Alves et al. (2020) realizaram uma pesquisa sobre carbono orgânico e atributos físico-químicos de solos no município de Paragominas e constaram que atributos como cor, $\mathrm{PH}$, umidade natural, textura e o teor de matéria orgânica possibilitam avaliar processos de modificação no uso do solo e identificar os impactos gerados.

Ademais, segundo Soares (2016), a consciência dos impactos ocasionados pelos vários sistemas de manejo do solo é fundamental para o melhoramento nas qualidades físicas e químicas do horizonte, visto que, o manuseamento impróprio e com o uso de técnicas inadequadas é capaz de desencadear o crescimento na densidade, perda da macroporosidade e porosidade, dentre outras 
carências. Este fato também pode ser evidenciado em estudo realizado por Carvalho (2014), já que distintas características do horizonte vão ser implementados para determinar as mudanças (densidade e porosidade) da forma de utilização do solo.

\section{Materiais e Métodos}

\section{1 Área de estudo}

A área de estudo está situada no município de Paragominas (Figura 1), localizado na mesorregião sudeste paraense, às margens da BR 010 (Belém-Brasília), principal via de acesso entre o município e a capital, além disso, o município é constituído por uma extensão territorial de aproximadamente 19.330 quilômetros quadrados (Andrade, 2011).

Figura 1 - Mapa político e geográfico do Município de Paragominas-PA.
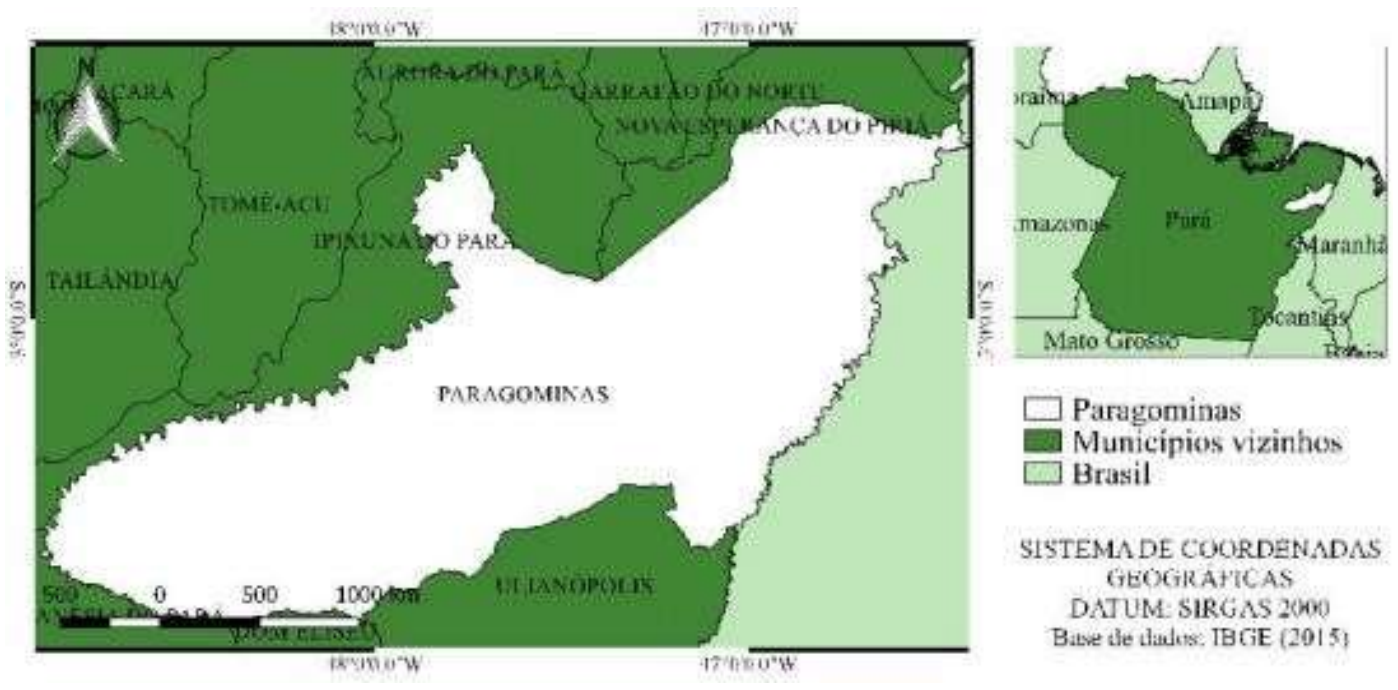

Fonte: Giuliatti et al. (2019).

De acordo com o senso do IBGE (2019), o município apresenta população estimada em 113.145 habitantes, na qual as principais atividades geradoras de renda são a pecuária, com mais ou menos 490.000 ha de pastagens, e a agricultura.

Segundo pesquisa elaborada por Pinto et al. (2009), o município de Paragominas apresenta clima caracterizado por ser do tipo quente e úmido, com temperatura média anual que varia entre 25 e $26{ }^{\circ} \mathrm{C}$ e umidade relativa do ar, com média igual a 81\%. Em relação a classificação dos índices de precipitação, ele decorre entre dezembro e maio, todavia, com diminuição de PRP entre junho e novembro.

Quanto a classificação do solo no município, a partir do relatório emitido pela prefeitura de Paragominas (2018), podese verificar que os Latossolos Amarelos são os mais presentes na região. E, ainda existem algumas variações, como por exemplo: Latossolo Amarelo com textura muito argilosa, Latossolo Amarelo com textura argilosa e Concrecionários Lateríticos, Latossolos com textura média e Areias Quartzosas. Ademais, observa-se a presença de Solos Aluviais e Solos Indiscriminados nas zonas de várzea.

\subsection{Material}

\section{Amostragem do solo}

Nesta pesquisa utilizaram-se duas amostras, de dois horizontes $(0-20 \mathrm{~cm}$ e $20 \mathrm{~cm}-40 \mathrm{~cm})$, do perfil de solo identificado como Latossolo Amarelo Distrófico, de acordo com o Sistema Brasileiro de Classificação de Solos (Embrapa, 2013). 
Os materiais utilizados para a coleta das amostras de solo foram cedidos pelo Laboratório de Qualidade Ambiental (LQA), da Universidade do Estado do Pará (UEPA), em Paragominas- PA (Tabela 1).

Tabela 1 - Materiais usados para a coleta das amostras de solo.

\begin{tabular}{lll}
\hline Material & Quantidade & Utilidade \\
\hline Picareta & 1 & Identificação do ponto de escavação para perfuração \\
Fita métrica de 50m & 1 & Mensuração da distância entre os horizontes \\
Ferro vergalhão & 1 & Perfuração do solo \\
Pá de Bico & 1 & Remoção e transporte das amostras \\
Saco de coleta & 1 & Guardar as amostras coletadas \\
Fita isolante & 2 & Marcação do ferro vergalhão para identificar a \\
& profundidade de $0-20 \mathrm{~cm}$ e $20-40 \mathrm{~cm}$
\end{tabular}

Fonte: Autores (2020).

\subsection{Método da Pesquisa}

A abordagem desta pesquisa é quanti-qualitativa, pois para Silva e Fossá (2015), se fará necessário uma análise criteriosa de literaturas que abrangem o tema da pesquisa, com informações que serão usadas no respaldo da coleta para uma nova pesquisa.

O levantamento dos dados documentais ocorreu a partir de periódicos nacionais, tais como: biblioteca eletrônica (Scientific Electronic Library Online-SciELO), google acadêmico e google scholar que foram indexados com recorte temporal para os últimos 17 anos (2003-2020), porém com exclusiva atenção para os últimos 5 anos (2015-2020). A escolha deste recorte é justificada devido a importância de literaturas pioneiras sobre o tema a ser abrangido nesta pesquisa.

\subsection{Coleta do Solo}

As coletas das amostras de solo iniciaram-se às $09 \mathrm{hrs} 30 \mathrm{~min}$ com termino às $10 \mathrm{hrs} 00 \mathrm{~min}$ do dia 13 de outubro de 2020 , período pouco chuvoso na região. As amostragens ocorreram em um ponto pré-determinado dentro do Campus da UEPA.

Com o auxílio de uma pá, iniciaram-se as primeiras perfurações, na profundidade de $0-20 \mathrm{~cm}$. E posteriormente, na profundidade de $20 \mathrm{~cm}-40 \mathrm{~cm}$ (Figura 2a), de acordo com metodologia proposta por (Lemos e Santos, 1996).

Após a coleta das amostras de solos (Figura 2a) seguiu-se o protocolo de identificação e etiquetagem com as informações sobre o horizonte, ponto de coleta e profundidade (Figura 2b). 
Figura 2 -a) Coleta da amostra do horizonte do solo; b) Identificação e etiquetamento da amostra.

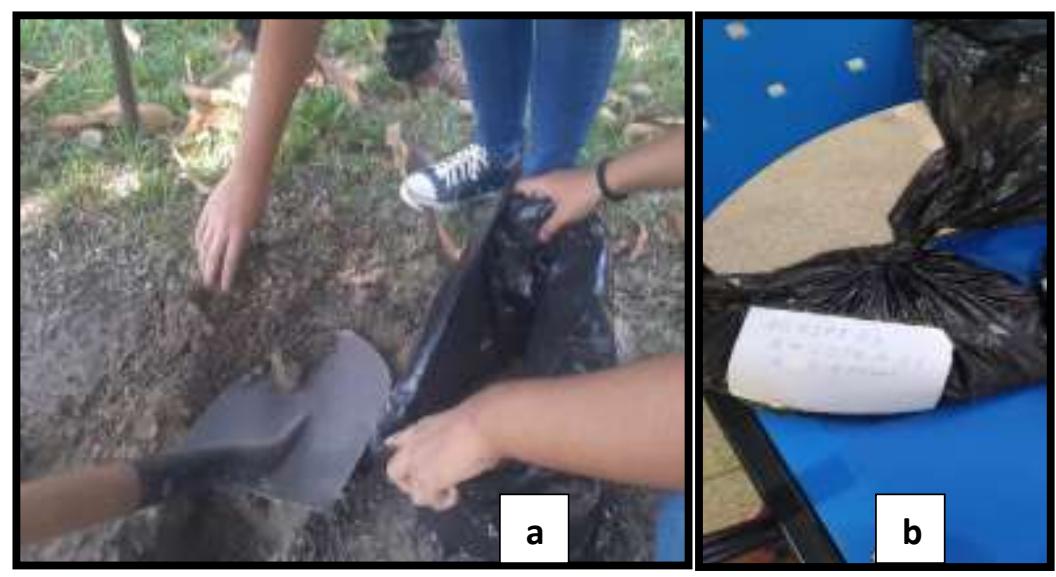

Fonte: Autores (2020).

\subsection{Análises Laboratoriais}

As duas amostras coletadas foram submetidas às análises laboratoriais (Tabela 2), para a verificação dos parâmetros físicos e químicos.

Tabela 2 - Parâmetros físicos e químicos do solo analisados laboratorialmente.

\begin{tabular}{lll}
\hline Parâmetros & Simbologias & Unidades de medida \\
\hline Potencial Hidrogeniônico em água & $\mathrm{pH}_{\mathrm{H} 2 \mathrm{O}}$ & -- \\
Matéria orgânica & $\mathrm{MO}$ & $\mathrm{g} / \mathrm{kg}$ \\
Textura/coloração & -- & -- \\
Granulométrica & -- & $\mathrm{Mm}$ \\
Teor de Umidade Natural & $\mathrm{W}$ & $\mathrm{g} / \mathrm{kg}$ \\
\hline
\end{tabular}

Fonte: Autores (2020).

Ressalta-se que antes da realização das análises laboratoriais houve a necessidade de executar procedimentos para preparação das amostras. E, posteriormente a execução dos ensaios laboratoriais.

\subsubsection{Preparação das amostras}

A preparação da amostra se deu conforme Manual de Métodos de Análise em Solos da Embrapa (2011).

\section{a) Quarteamento}

O processo de Quarteamento tem o objetivo de separar subamostras representativas, ou seja, a homogeneização da amostra inicial. Primeiramente, para realização deste processo, depositou-se a amostra $1(0-20 \mathrm{~cm}) \mathrm{em}$ uma mesa de madeira devidamente higienizada, posteriormente espalhando-a e dividindo em quatro partes iguais (Figura 3a e 3b). 
Figura 3 - a) Amostra bruta coletada; b) Processo de quarteamento: divisão da amostra em quatro partes.

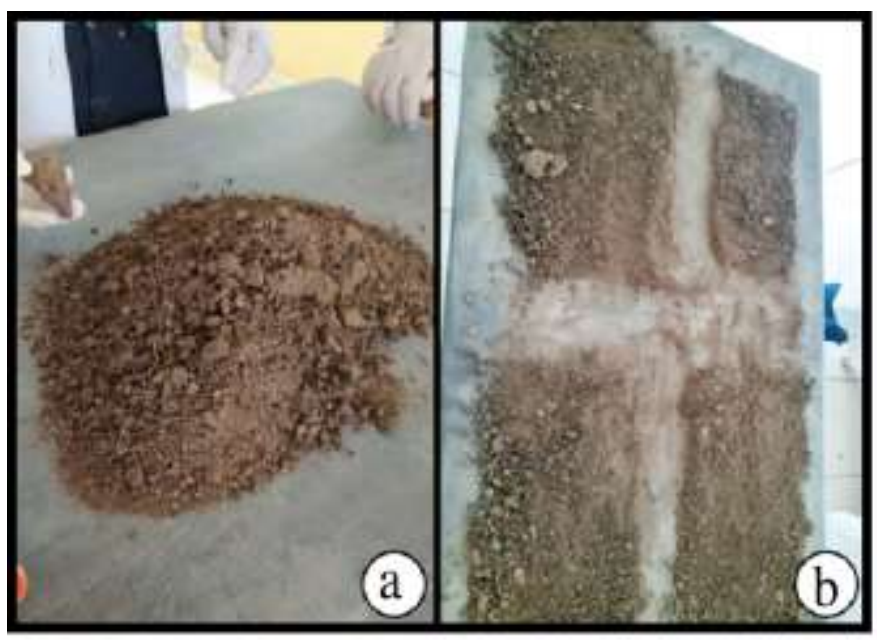

Fonte: Autores (2020).

\section{b) Destorroamento}

Com a etapa da limpeza finalizada, é feito o destorroamento que consiste em desagregar as partículas maiores de solo. Com o auxílio de um rolo de madeira iniciou-se o destorroamento pressionando o rolo contra a amostra até desagregar os torrões (Figura 4). Deve-se tomar cuidado na realização desta etapa, pois não se deve reduzir o tamanho natural das partículas de pedra, pois também serão importantes para caracterização do solo, durante o experimento.

Após o destorroamento total da amostra, esta foi novamente guardada em um saco de polipropileno, hermeticamente fechado e devidamente identificado. Os procedimentos de quarteamento, limpeza e destorroamento foram também feitos na amostra $2(20-40 \mathrm{~cm})$ e posteriormente guardada com os mesmos cuidados.

Figura 4 - a) Recolhimento de impurezas, como raízes; b) Destorroamento da amostra em partículas menores.

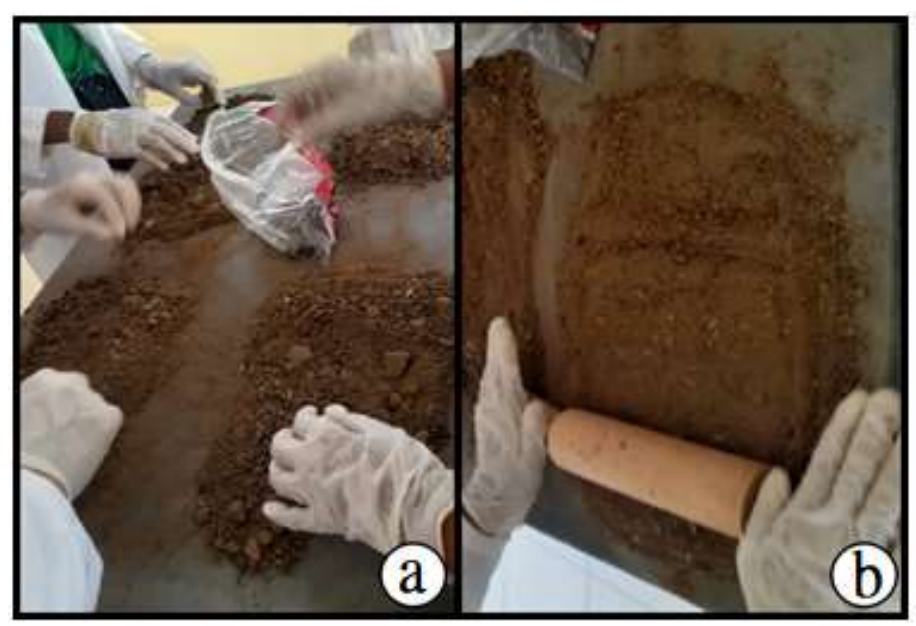

Fonte: Autores (2020).

\subsubsection{Parâmetros físicos}

\section{Umidade}

Sobre a verificação da umidade do solo utilizou-se 2 béqueres de $400 \mathrm{ml}$. Em seguida, realizou-se a identificação do primeiro béquer com a amostra $1(0-20 \mathrm{~cm})$ e o segundo com a amostra $2(20-40 \mathrm{~cm})$. Para o procedimento de pesagem das amostras, primeiramente realizou-se o procedimento de tara do béquer (Figura 5). 
Figura 5 - a) Pesagem do béquer vazio: Tara do béquer; b) Pesagem da amostra.

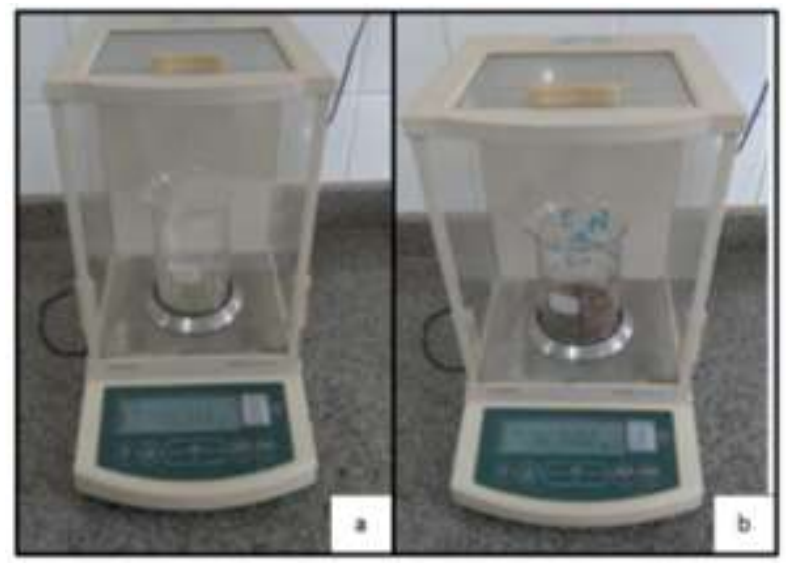

Fonte: Autores (2020).

Com a finalização deste processo, os béqueres 1 e 2 com as respectivas amostras úmidas pesadas, foram transferidos para a estufa a $60^{\circ} \mathrm{C}$, deixando nesta condição durante o período de 24 horas (Figura 6).

Figura 6 - Estufa de secagem com as amostras 1 e 2 .

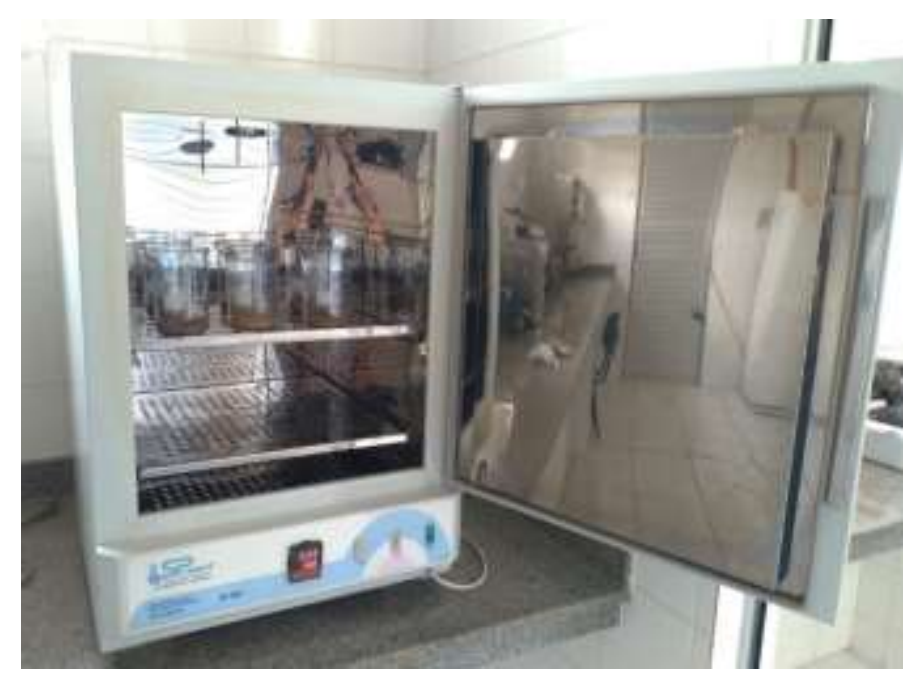

Fonte: Autores (2020).

\section{Cor da amostra (comparação de horizontes)}

Para classificar a coloração das amostras de solo foram utilizadas as cores do espectro eletromagnético: vermelho, laranja, amarelo, verde, ciano, azul e violeta, seguindo metodologia proposta na Carta de Munsell (1975). Com o auxílio da tabela de Munsell foram classificadas as (1) cores dominantes, (2) grau de claridade e (3) o croma. Ressalta-se que foram utilizadas amostras secas.

Através da tabela de Munsell obteve-se a cor dominante ou matiz, que pelo comprimento de onda da luz refletida no solo se saberá a matiz das amostras. Nesta pesquisa, as amostras analisadas obtiveram matiz com coloração vermelha para ambas as coletas. Logo depois, foi feito o grau de claridade da luz que se refere ao tons de cinza presentes na escala de 0 a 10 , na amostra $1(0-20 \mathrm{~cm})$ obteve-se o valor ' 9 ' e para amostra $2(20-40 \mathrm{~cm})$ o valor ' 8 '. 
Posteriormente, foi analisado o croma, que se refere a uma dimensão do sistema Munsell de cor e que corresponde mais estritamente à saturação, ou seja, é onde a cor mais se aproxima da verdadeira tonalidade, também na escala de 0 a 10. A amostra 1 teve a maior proximidade com o valor de'1', enquanto a amostra 2 obteve-se o valor ' 2 '.

\section{Mensuração do pH}

O Potencial Hidrogeniônico $(\mathrm{pH})$ foi executado de duas formas: caseiro e a utilização de um pHmetro de bancada, com a finalidade de comparar se o método caseiro é eficaz para a mensuração do pH, e se as características químicas (básico e ácido) encontradas nestes métodos distintos, são aproximados.

\section{a) Método caseiro}

A princípio optou-se em realizar a mensuração do $\mathrm{pH}$ de forma caseira, no qual, o primeiro passo para este procedimento é colocar 5 colheres da amostra $1(0-20 \mathrm{~cm})$ em um copo de plástico. No segundo passo, deve-se despejar uma quantidade pequena de água no copo com a amostra, misturando cuidadosamente e observando a quantidade de líquido que está sendo usada. No último passo, com o auxílio de uma colher colocou-se o bicarbonato de sódio $\left(\mathrm{NaHCO}_{3}\right)$, misturando-o com a amostra contendo a água.

Em outro copo este irá receber o ácido acético $\left(\mathrm{CH}_{3} \mathrm{COOH}\right)$. Com uma pequena porção (5 colheres) da amostra 1 (0$20 \mathrm{~cm}$ ) contida no copo de plástico, é misturado uma colher de sopa de $\mathrm{CH}_{3} \mathrm{COOH}$. Estes dois procedimentos (bicarbonato de sódio e ácido acético) também foram efetuados com a amostra $2(20-40 \mathrm{~cm})$.

Verificou-se que após 20 minutos, ocorreram mudanças (presença de bolhas) nas amostras 1 e 2 que continham o bicarbonato de sódio (Figura 7a; b).

Figura 7 - a) Amostra 1 com $\mathrm{NaHCO}_{3} ;$ b) amostra 2 com $\mathrm{NaHCO}_{3}$.

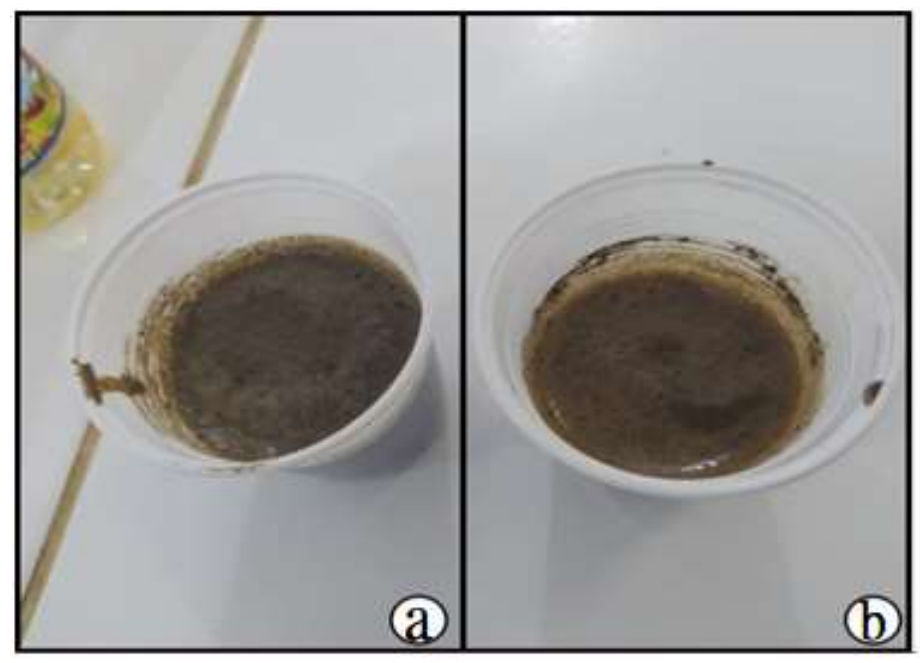

Fonte: Autores (2020).

Em relação ao $\mathrm{CH}_{3} \mathrm{COOH}$, as amostras não apresentaram mudanças (Figura 8a; b). Isto é explicado em razão do comportamento do solo ao reagir com as soluções químicas, pois, se a amostra contendo o bicarbonato de sódio efervescer após um período de 10 a 20 minutos, esta será classificada como ácida. 
Figura 8 - a) amostra 1 com $\mathrm{CH}_{3} \mathrm{COOH}$; b) amostra 1 com $\mathrm{CH}_{3} \mathrm{COOH}$.

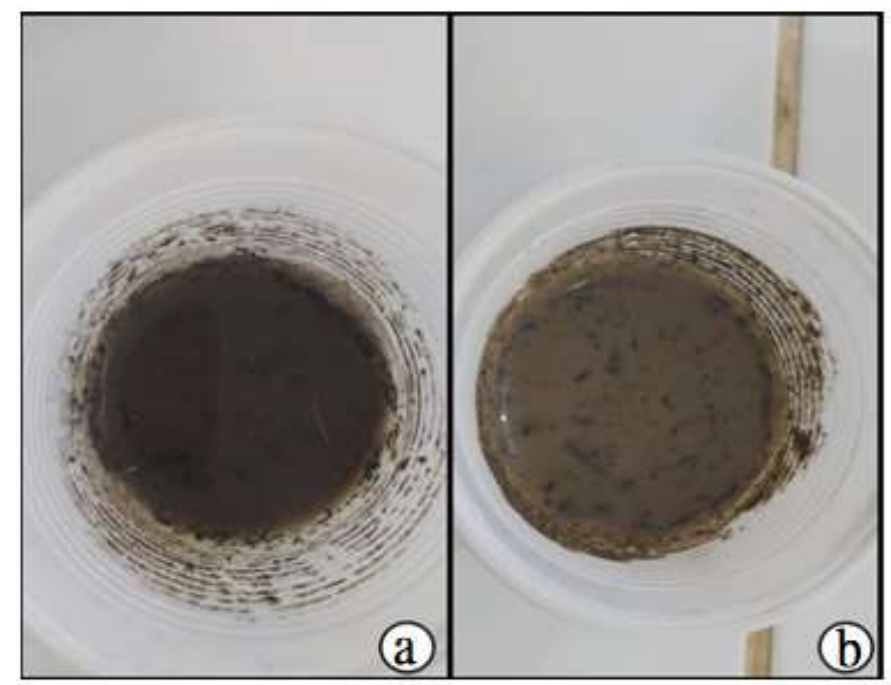

Fonte: Autores (2020).

Caso a amostra reaja com o ácido acético, formando bolhas na superfície da mesma, esta será classificada como alcalina. Na ocorrência em que a amostra não apresente mudanças em sua superfície, esta será classificada como neutro.

\section{b) Phmetro de bancada}

Para a determinação da concentração do pH foi utilizado o pHmetro de bancada, que é específico para a cotação de amostras em meio aquoso. Para tal ação, o equipamento foi ligado, em seguida iniciou-se o processo de calibração.

Em um béquer de $50 \mathrm{ml}$ foi adicionado $25 \mathrm{ml}$ de ácido acético $\left(\mathrm{CH}_{3} \mathrm{COOH}\right)$ usado para fazer a limpeza do eletrodo, pois é sensível à impurezas que podem vir a interferir na leitura precisa das amostragens. O eletrodo foi adicionado dentro do béquer contendo o ácido, em seguida, ele foi ambientado com água destilada em outro béquer de 500ml, e por fim, foi limpo com papel toalha especifico para a higiene do equipamento.

Por conseguinte, iniciou-se o processo de preparação da primeira amostragem $(0-20 \mathrm{~cm})$ que estava em um béquer de 250ml. Nesta etapa final, com o auxílio de um bastão de vidro foi efetuado a homogeneização do solo para que as partículas pudessem se dissolver. A partir de então realizou-se a leitura do parâmetro pH.

Após a análise com o uso do pHmetro de bancada, também foi aplicado a técnica de leitura com as fitas universais que são um meio mais simples e rápido para mensuração de soluções através do uso de cores diferentes para cada escala de pH. $\mathrm{Na}$ pesquisa em questão, o intuito foi observar se os valores entre os dois meios usados na amostragem da solução em análise apresentavam similaridades.

Vale salientar que o método aplicado na primeira amostra, também foi realizado para segunda amostragem do solo $(20-40 \mathrm{~cm})$.

\section{Granulometria}

No que se refere a etapa de verificação granulométrica das amostras coletadas, fez-se necessário o uso de duas peneiras granulométricas de aço inox (Tabela 3). 
Tabela 3 - abertura de peneiras granulométricas.

\begin{tabular}{ll}
\hline \multicolumn{2}{l}{ Peneiras Granulométricas } \\
$\mathrm{N}^{\circ}$ & Malhar \\
35 & $500 \mu \mathrm{m}$ \\
60 & $250 \mu \mathrm{m}$ \\
\hline
\end{tabular}

Fonte: Autores (2020).

Inicialmente as duas peneiras foram postas uma sob a outra com a utilização da técnica de empilhamento, onde a maior malha (35) foi sobreposta na menor malha (60), este procedimento foi necessário para que as amostras mais grossas fossem receptadas na primeira peneira, e só fosse repassado para a segunda peneira, as amostras mais finas, restando assim, somente as partículas de menor granulometria que ficarão no recipiente.

Ao iniciar o processo de separação granulométrica das amostras coletadas o fracionamento ocorrerá conforme as dimensões dos materiais sólidos presentes, sendo agitadas de forma manual e, ao término do processo terá ocorrido a divisão das partículas e dos agregados.

Com o peneiramento, é possível obter três tipos de massa específica do solo (1) amostra grossa (2) amostra fina (3) amostra super fina e, desta forma, cada quantidade é transportada da peneira para o béquer com a utilização de um funil de papel para que ocorra a verificação da massa especifica na balança analítica (figura 9a; b; c).

Figura 9 - a) encaixe das peneiras e agitação b) despejamento fracionado da amostra por meio de funil de papel c) determinação da massa específica da amostra fracionada.

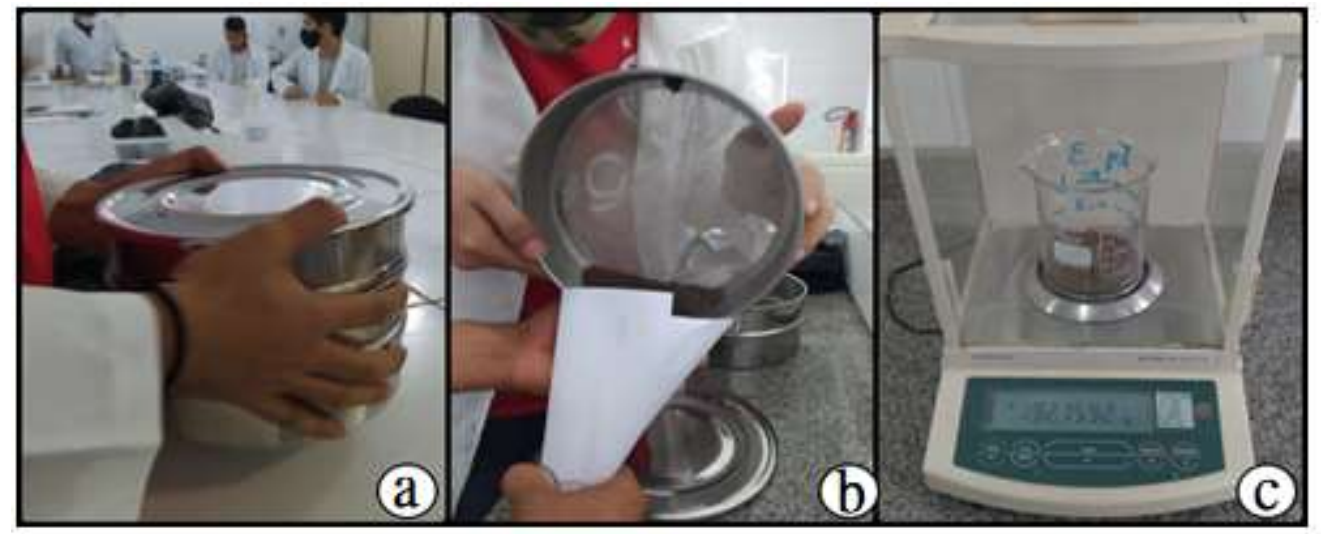

Fonte: Autores (2020).

Com a verificação da amostra fracionada na balança, já é possível determinar a quantidade, em porcentagem de areia, silte e argila presentes na amostra. Logo, com os valores já determinados, são posteriormente adicionados ao triângulo de classificação textural dos solos adotado pela Empresa Brasileira de Pesquisa Agropecuária (EMBRAPA) para determinar a textura da amostra. 


\section{Teor de carbono orgânico}

No que concerne a determinação do teor de matéria orgânica das amostras de solo analisadas, utilizou-se o Método Walkley-Black modificado, sendo o mesmo caracterizado pela oxidação a $\mathrm{CO}_{2}$, por íons dicromato, realizado em meio fortemente ácido.

Na oxidação da matéria orgânica, foi utilizado o calor desprendido do ácido sulfúrico $\left(\mathrm{H}_{2} \mathrm{SO}_{4}\right)$ como fonte de energia, sendo que o excedente de dicromato após esse procedimento foi posteriormente titulado com solução padrão de sulfato ferroso amoniacal (sal de Mohr).

As duas amostras de solo analisadas, tanto a amostra 1 do primeiro horizonte $(0-20 \mathrm{~cm})$, e a amostra 2 do segundo horizonte $(20-40 \mathrm{~cm})$ foram submetidas ao procedimento de titulação para determinar o teor do carbono orgânico.

Para análise do solo pesou-se 20g de cada amostra, que foram passadas em uma peneira de $80 \mathrm{mesh}$, depois se separou 0,5g de cada amostra em um erlenmeyer de $250 \mathrm{ml}$. Em seguida foram adicionados $10 \mathrm{ml}$ pipetados da solução de dicromato de potássio, colocou-se um tubo de ensaio de $25 \mathrm{~mm}$ de diâmetro e $250 \mathrm{~mm}$ de altura cheio de água na abertura do erlenmeyer, para este funcionar como um condensador, e posteriormente aqueceu-se a solução em uma placa elétrica até atingir uma fervura branda, em 5 minutos. Deixou-se esfriar a solução, e logo depois foram adicionados $80 \mathrm{ml}$ de água destilada, medida em proveta, $2 \mathrm{ml}$ de ácido ortofosfórico e 3 gotas do indicador de difenilamina, após o preparo o mesmo foi levado para titulação.

Para o preparo da solução de sulfato ferroso amoniacal $0,1 \mathrm{~N}$, que foi usado na titulação, primeiramente deve-se pesar na balança 40 gramas de $\mathrm{Fe}\left(\mathrm{NH}_{4}\right)_{2} 6 \mathrm{H}_{2} \mathrm{O}$ cristalizado, (sal de Mohr) e logo após dissolvê-lo em $500 \mathrm{ml}$ de água, contendo o ácido sulfúrico, que deste, foi retirado $10 \mathrm{ml}$ com o auxílio de uma pipeta volumétrica de $20 \mathrm{ml}$ (para o manuseio de soluções ácidas, utilizar a capela de exaustão).

Após a mistura, agitando manualmente o balão com o sulfato ferroso amoniacal contendo água, juntamente com o ácido sulfúrico, necessita-se completar novamente com água até alcançar a marca de 1 litro no balão volumétrico. Com a solução pronta, esta foi aferida na bureta de $50 \mathrm{ml}$, devidamente ajustada no suporte. Neste momento com o titulante dentro da bureta, este é despejado em forma de gotejamento no erlenmeyer contendo o titulado que foi previamente posicionado em baixo da torneira da bureta, no qual, deve-se fazer movimentos circulares durante a titulação para que o titulante seja dissolvido corretamente no titulado até ocorrer a mudança de cor da amostra de azul para verde, conforme o Método Walkley-Black. Este procedimento foi realizado para a amostra $1(0-20 \mathrm{~cm})$ e amostra $2(20-40 \mathrm{~cm})$.

Em relação as amostras de solo coletadas e analisadas, efetuou-se o seguinte cálculo (Equação 1,2 e 3), para obter-se a quantidade de carbono e sucessivamente, de matéria orgânica presente na amostra.O cálculo para a obtenção da percentagem de matéria orgânica é a multiplicação do resultado obtido de carbono orgânico por 1,724. Isto ocorre devido a composição média do húmus, onde o carbono participa com $58 \%$. 


\section{$f=40 /$ volume de sulfato ferroso aminiacal na prova em branco}

$$
\mathrm{C}\left(\frac{g}{\mathrm{~kg}}\right)=(40-\text { volume gasto }) \times f \times 0,6
$$

$$
\text { Matéria Orgânica }\left(\frac{g}{\mathrm{~kg}}\right)=\mathrm{C}\left(\frac{g}{\mathrm{~kg}}\right) \times 1,724
$$

\section{Resultados e Discussão}

No quesito umidade do solo utilizou-se a amostra 1 (189,544 gramas) ainda úmida e também a seca (após o procedimento de secagem na estufa) no qual obteve-se 189,544 gramas. Repetindo-se para amostra 2 úmida (214,1404 gramas) e seca $(209,2547$ gramas). Para encontrar a taxa de umidade natural, necessita-se subtrair o peso da amostra úmida com o peso da amostra seca (Equações 4 e 5).

Amostra $1(0-20 \mathrm{~cm}): 192,7592 \mathrm{~g}-189,544 \mathrm{~g}=3,2152 \%$ (4)

Amostra $2(20-40 \mathrm{~cm}): 214,1404 \mathrm{~g}-209,2547 \mathrm{~g}=4,8857 \%$ (5)

A diferença entre a taxa de umidade natural dos horizontes do solo estudados se faz em razão dos níveis de energia de um local ou condição. Isto pode ser explicado usando o exemplo da passagem da água de um solo úmido para o seco, onde observa-se a direção e a taxa de movimento da água no solo e nas plantas (VIEIRA et al., 2020). Vale salientar, que de acordo com Santos et al. (2020) a capacidade de acúmulo de água e também a velocidade da umidade dos horizontes variam de solo para solo, de acordo com suas características físicas e químicas, sendo estes, comportamentos que foram resultados da ação conjunta de diversos fatores (vegetação, intervenção antrópica, etc.).

Kazmierczak (2018) observou que a presença de água no solo influencia na quantidade de radiação eletromagnética recebida, ou seja, uma razão direta entre a quantidade de água no solo e a cor. Isto significa que quanto mais úmido estiver o solo maior é a tendência da cor do solo mostrar-se escura.

Outro fator importante a ser discutido, segundo Barbosa et al. (2019) que efetuaram uma pesquisa sobre a variação temporal da umidade do solo sob diferentes coberturas vegetais, no qual, enfatizam que a cobertura do solo afeta profundamente a capacidade de infiltração de água, e conseqüentemente interferindo na disponibilidade de água para as plantas, isto envolve a densidade de espécies arbóreas e a forma em que é praticado o manejo do solo, que influenciam na distribuição da água sobre os horizontes. 
Isto pode ser verificado no local em que as amostras foram coletadas, que possui como principal característica a presença de espécies arbóreas como mangueiras (mangifera indica l.), gramíneas (cynodon dactylon) e serapilheiras, deste modo, oferecendo ao solo, teores de matéria orgânica (MO).

Os dados obtidos e analisados indicaram que a cor predominante nas amostragens foi a vermelha $(\mathrm{R})$, enquanto que $\mathrm{o}$ grau de claridade no valor de 8 para a primeira amostra e valor 9 para a segunda. Em relação ao croma, foi observado que os valores obtidos detinham similaridades, haja em vista que o valor para a primeira coleta foi equivalente a 1 e na segunda coleta foi igual a 2. Deste modo, pode-se afirmar que croma e grau de claridade são parâmetros inversamente proporcionais, pois enquanto a eficiência do grau de claridade é mais próxima de dez o croma será mais próximo de zero.

Indicação da cor do solo das amostras:

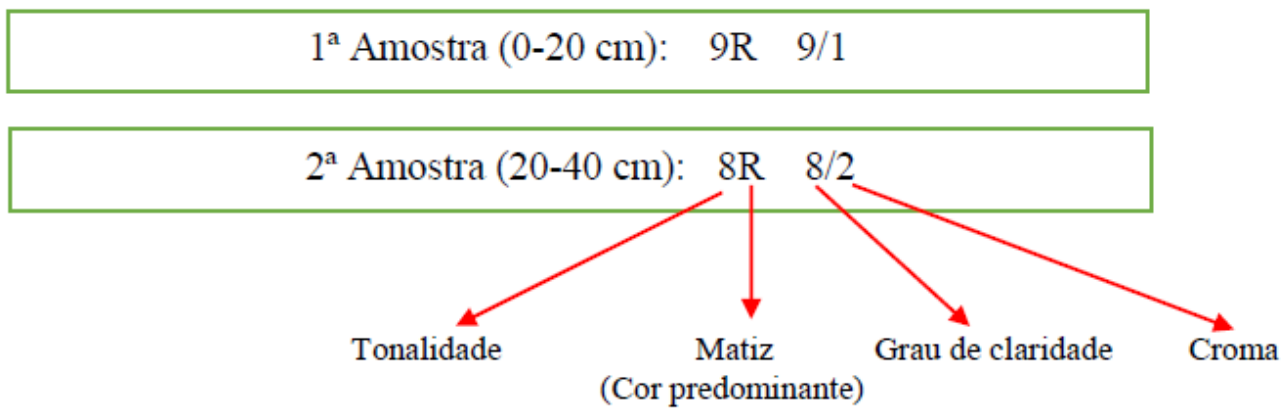

Guimarães (2015) realizou uma pesquisa exploratória sobre determinação de cores dos solos na bacia hidrográfica do rio Marombas (SC) e os dados por ele obtidos indicaram que a cor é a primeira característica a ser notada ao examinar o solo, pois a mesma é empregada para distinguir e especificar os horizontes do mesmo, além disso é por meio dela que se consegue observar o tipo de mineral existente na amostra e a quantidade de matéria orgânica existente, ainda segundo o autor o principal componente responsável pela modificação do solo é o oxido de ferro $\left(\mathrm{Fe}_{2} \mathrm{O}_{3}\right)$, isso porque ele deixa uma aparência amarela e/ou avermelhada do solo. Logo, ambas as pesquisas apresentam similaridades.

A partir do método caseiro para determinar o pH utilizando como reagentes o bicarbonato de cálcio e o ácido acético, constatou-se um caráter ácido, tanto da amostra de solo do horizonte $1(0-20 \mathrm{~cm})$, quanto da amostra $2(20-40 \mathrm{~cm})$.

No segundo método para determinação do pH realizado através do pHmetro de bancada, a amostra de solo do primeiro horizonte $(0-20 \mathrm{~cm})$, apresentou um pH de 5,55, já na amostra do segundo horizonte $(20-40 \mathrm{~cm})$ resultou em um pH de 4,92. Vale mencionar também que foi feito a verificação do $\mathrm{pH}$ de ambas as amostras através da fita universal indicadora de $\mathrm{pH}$, na primeira amostra $(0-20 \mathrm{~cm})$ o resultado foi próximo de 6 , na segunda amostra $(20-40 \mathrm{~cm})$, o resultado foi próximo de 5 .

A justificativa para os valores de $\mathrm{pH}$ medidos pela fita indicadora não terem sido os mesmos do pHmetro de bancada, apenas próximos dos mesmos, se justifica pelo fato de o primeiro ser impreciso e feito manualmente através de observação e comparação visual.

Conforme Bello et al. (2020) os solos da região amazônica são em sua grande maioria ácidos, apresentando baixos níveis de fertilidade, assim como disponibilidade de nutrientes para atender a flora característica local, a exemplo do cálcio $(\mathrm{Ca})$, fósforo $(\mathrm{P})$ e potássio $(\mathrm{K})$. Sendo essas características ocasionadas pelas elevadas temperaturas e alta precipitação, aliada a formação geológica da região. Dessa forma, os dados do pH das amostras de solo analisadas em laboratório, corroboram com a afirmação do autor, já que o município de Paragominas, em que foram coletadas as amostras, se encontra na região amazônica, justificando assim, a acidez do solo. 
Segundo Rodrigues et al. (2003), a maior parte do solo do município de Paragominas é o Latossolo Amarelo Distrófico, apresentando alto grau de intemperismo, elevada profundidade, de caráter ácido e ricos em alumínio. A acidez mencionada pelo autor em seu estudo do solo de Paragominas, novamente reforça os resultados obtidos em laboratório do pH das amostras analisadas.

Verificou-se que para a distribuição granulométrica das amostragens, ou seja, a textura que foram submetidas as análises laboratoriais, as partículas de areia foram as mais frequentes na amostra 2, com percentual de 46\% (Tabela 4).

Tabela 4 - valores de massa especifica.

\begin{tabular}{llllll}
\hline Granulometria & Peneira & Amostra A (0-20 cm) & Amostra B (20-40cm) \\
Fração & $\mathrm{N}^{\circ}$ Malha & Peso $_{(\mathrm{g})}$ & $\%$ & Peso(g) & $\%$ \\
Areia & 35 & 33,256 & 33 & 45,739 & 46 \\
Silte & 60 & 26,782 & 27 & 31.638 & 32 \\
Argila & Total & 40,014 & 40 & 22,623 & 22
\end{tabular}

Fonte: Autores (2020).

Em relação às demais partículas verificadas, a partir dos dados obtidos e analisados constatou-se que a argila foi a mais predominante (40\%) na primeira amostragem, enquanto que o silte deteve de um percentual de $32 \%$, sendo observado os maiores valores na segunda amostra, o que representa uma diferença de aproximadamente $24 \%$ entre a areia e a argila. Desse modo, pode-se verificar que as partículas presentes na segunda amostra $(20-40 \mathrm{~cm})$, sobressaíram-se em relação a primeira amostra $(0-20 \mathrm{~cm})$.

O triângulo textural demonstrou que as duas amostras analisadas nesta pesquisa (figura 10a; b ) são caracterizadas como textura franco-argilosa, também conhecida como textura média. Portanto, é definida como solos que apresentam proporções similares de partículas de areia, silte e argila, no qual, estas características proporcionam boa drenagem e capacidade de retenção de água, além do índice médio de erodibilidade (CENTENO et al., 2017).

Figura 10 - Triângulo textural.

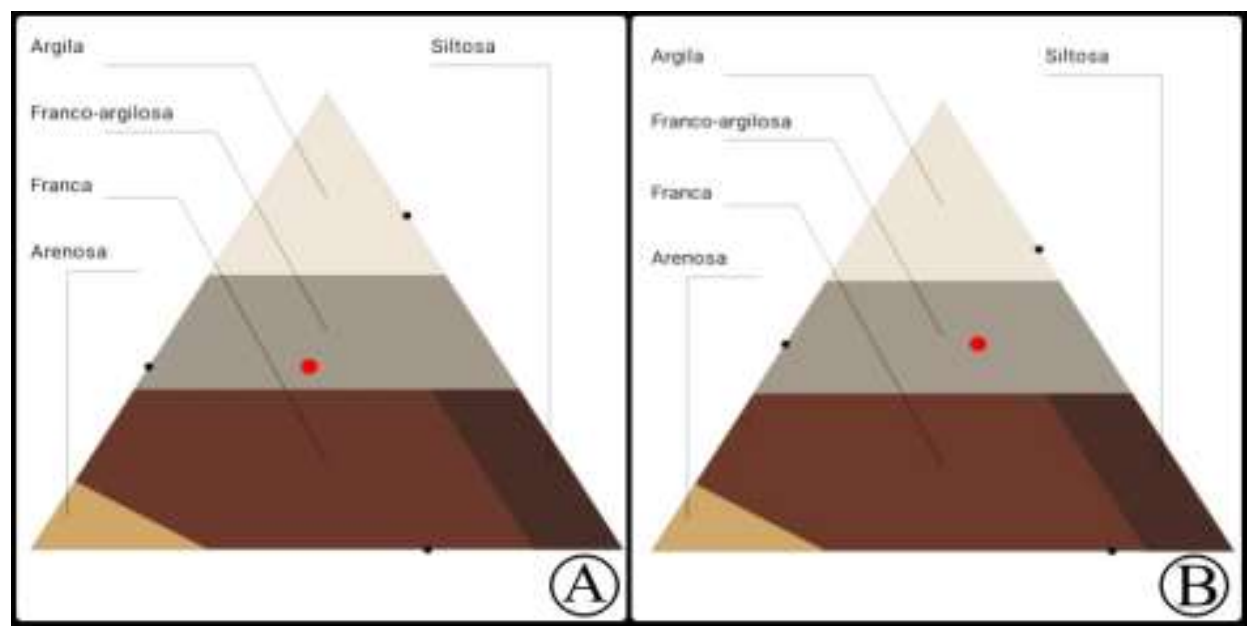

Fonte: Autores (2020). 
Quanto à avaliação do teor de carbono (C), Carmo e Silva (2012) afirmam que há variações nos resultados, que geralmente ocorrem em razão dos métodos empregados, ou devido à composição química dos materiais analisados. Neste viés, observa-se que estes podem ter sido os motivos da discrepância na coloração das amostras 1 e 2, após tituladas, (Figura 11).

Figura 11 - Amostras 1 e 2 após serem tituladas.

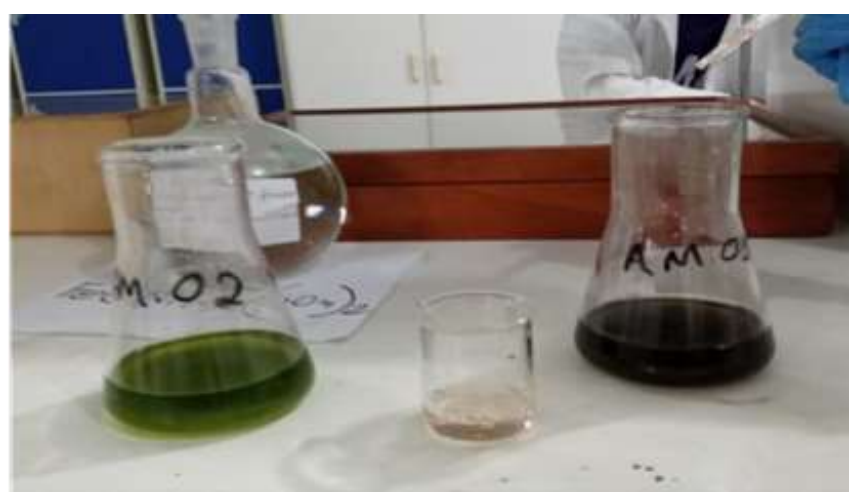

Fonte: Autores (2020).

Esta diferença foi verificada durante o procedimento de titulometria, onde a amostra 1 utilizou de $100 \mathrm{ml}$ de titulante e não demonstrou modificações em sua coloração, isto é, não completou sua titulação, assumindo a coloração verde escuro. Já a amostra 2, com apenas 14,5 ml de titulante transformou-se de um azul escuro à um verde.

Portanto, os resultados alcançados, possivelmente, indicam que houve resistência à oxidação na amostra 1, e esta devese a outras condições, como, por exemplo, a proteção da matéria orgânica por minerais e a insistência química específica de alguns fragmentos orgânicos dos resíduos. Ainda sob essa perspectiva, Eusterhues et al. (2005) corroboram esta ideia e afirmam que a presença de frações de $\mathrm{C}$ carbonizadas nos resíduos aumentam o grau de recalcitrância da matéria orgânica.

Em relação ao percentual de teor matéria orgânica resultante de carbono orgânico da amostra 1, este foi de $-49,65 \%$. Nesse sentido, o resultado final de $\mathbb{\Xi}$ encontrado foi de 0,8 apesar de não teratingindo o valor correto que era 1 , o resultado ficou em uma faixa bem aproximada doesperado. Este fato pode ser explicado por erros no momento do experimento, como na pesagem dos reagentes primários, excesso na quantidade volumétrica do titulante no titulado ou na quantidade de ácido. Estes fatos também podem ser explicados pela insistência química de alguns fragmentos, como já havia sido citado anteriormente, impossibilitando a mudança na coloração da amostra após sua titulação.

Quanto ao percentual da amostra 2, este foi de 12,24\% de matéria orgânica. Visto que a amostra não teve dificuldade para chegar ao ponto de titulação observa-se que a mesma teve baixa concentração de matéria orgânica, possibilitando a oxidação através da solução de dicromato de potássio, e demonstrando melhores resultados quanto ao procedimento laboratorial.

\section{Considerações Finais}

Apesar de, até o presente não existir um método prático e confiável para estimar a qualidade do solo, é consensual a mensurar-se através de indicadores físico, químicos e biológicos e relacioná-lo a sua funcionalidade. Portanto, os resultados obtidos através de indicadores físicos e químicos nesta pesquisa podem ser utilizados para avaliação da qualidade do solo para fins de agricultura e pecuária.

Ademais, a caracterização físico-química realizada expõe a importância de realização de análise campo-laboratório dos solos como ferramenta para compreender processos de modificação da paisagem, e conseqüentemente do solo no local em estudo. 
Em suma, com base no conhecimento adquirido, foi possível observar que o solo das amostras utilizadas para as análises laboratoriais dos atributos físico-químicos indicaram baixa dissemelhança entre si, apresentando resultados pouco distintos apesar da mudança de horizonte.

\section{Agradecimentos}

Os autores agradecem a Universidade do Estado do Pará (UEPA), especialmente o Laboratório de Qualidade Ambiental, do campus Paragominas.

\section{Referências}

Alves, C. N., de Sousa Miranda, L. A., Farias, T. L., do Nascimento, J. M. H., dos Santos Silva, M., \& dos Santos, F. F. (2020). Carbono orgânico e atributos físico-químicos de um solo do município de Paragominas-PA. Research, Society and Development, 9(11), e98191110518-e98191110518.

Barbosa, R. A., de Faria, R. S., da Silveira, L. J., Dias, H. C. T., Pimenta, L. V. A., de Souza, C. M., \& Ferreira, A. C. S. (2019). Variação Temporal Da Umidade Do Solo Sob Diferentes Coberturas Vegetais. Revista Ifes Ciência, 5(2), 11-23. https://doi.org/10.36524/ric.v5i2.443

Giuliatti, N., Rodrigues, A. B., Jesus, E., \& Junior, A. P. (2019). Variabilidade da precipitação mensal e anual no município de Paragominas-PA. Enciclopédia Biosfera, 16(29). 10.18677/encibio_2019a133

da Cunha Bello, O., da Cunha, J. M., Lima, R. A., Querino, C. A. S., \& Campos, M. C. C. (2020). Deposição E Aporte De Nutrientes Via Serapilheira Em Ecossistema De Floresta Amazônica. Revista Gestão \& Sustentabilidade Ambiental, 9(3), 282-297. http://dx.doi.org/10.19177/rgsa.v9e32020282-297

Carmo, D. L. D., \& Silva, C. A. (2012). Métodos de quantificação de carbono e matéria orgânica em resíduos orgânicos. Revista Brasileira de Ciência do Solo, 36(4), 1211-1220. https://doi.org/10.1590/S0100-06832012000400015

Carneiro, M. A. C., Souza, E. D. D., Reis, E. F. D., Pereira, H. S., \& Azevedo, W. R. D. (2009). Atributos físicos, químicos e biológicos de solo de cerrado sob diferentes sistemas de uso e manejo. https://doi.org/10.1590/S0100-06832009000100016

Carvalho, M. A. D., Ruiz, H. A., Costa, L. M. D., Passos, R. R., \& Araujo, C. A. D. S. (2014). Composição granulométrica, densidade e porosidade de agregados de Latossolo Vermelho sob duas coberturas do solo. Revista Brasileira de Engenharia Agrícola e Ambiental, 18(10), 1010-1016. https://doi.org/10.1590/18071929/agriambi.v18n10p1010-1016

Carvalho, T. S. (2014). [dissertação]. Uso do solo e desmatamento nas regiões da Amazônia legal brasileira: condicionantes econômicos e impactos de políticas públicas.

Centeno, L. N., Guevara, M. D. F., Cecconello, S. T., de Sousa, R. O., \& Timm, L. C. (2017). Textura do solo: conceitos e aplicações em solos arenosos. Revista Brasileira de Engenharia e Sustentabilidade, 4(1), 31-37. https://doi.org/10.15210/rbes.v4i1.11576

Cunha, E. D. Q., Stone, L. F., Ferreira, E. P. D. B., Didonet, A. D., \& Moreira, J. A. (2012). Atributos físicos, químicos e biológicos de solo sob produção orgânica impactados por sistemas de cultivo. Revista Brasileira de Engenharia Agrícola e Ambiental, 16(1), 56-63.

Doran, J. W., \& Parkin, T. B. (1994). Defining and assessing soil quality. Defining soil quality for a sustainable environment, 35, 1-21. https://doi.org/10.1590/S1415-43662012000100008

EMBRAPA. (2011). Manual de métodos de análise de solo. Embrapa Solos-Documentos (INFOTECA-E). https://www.infoteca.cnptia.embrapa.br/infoteca/bitstream/doc/990374/1/ManualdeMtodosdeAnilisedeSolo.pdf

Guerra, S. C., de Araújo Abrantes, F. J., Neto, E. L. G. R., de Azevedo, J. B., Tai, D. W., Ferreira, M. M., \& de Magalhães, M. S. INSTITUTO BRASILEIRO DE GEOGRAFIA E ESTATÍSTICA-IBGE.

Kazmierczak, R. (2018). [dissertação]. Indicadores físicos e químicos de qualidade do solo em sistemas de preparo.

Müller, R., Feiden, A., Gerke, L. V., Mari, A. G., \& Lucio, L. T. Atributos associados ao grau de compactação do solo e sua correlação com a produção agrícola. Acta Iguazu, 3(3), 131-137.

https://doi.org/10.48075/actaiguaz.v3i3.11083

Pinto, A., Amaral, P., Souza Jr, C., Verissimo, A., Salomão, R., Gomes, G., \& Balieiro, C. (2009). Diagnóstico socioeconômico e florestal do município de Paragominas. Belém: Imazon.

Paragominas.Lei n. 948 de 24 de outubro de 2017. Dispõe sobre o Plano Plurianual para o período 2018-2021 e dá outras providencias. Paragominas: Câmara Municipal,2017.

Queiroz, A. F. (2013). Caracterização e classificação de solos do município de Casa Nova-BA, para fins de uso, manejo e conservação [dissertação]. Mossoró: Universidade Federal Rural do Semiárido.

Rodrigues, T. E., Silva, R. D. C., Da Silva, J. M. L., De Oliveira Junior, R. C., Gama, J. R. N. F., \& Valente, M. A. (2003). Caracterização e classificação dos solos do município de Paragominas, Estado do Pará. Embrapa Amazônia Oriental-Documentos (INFOTECA-E).

Lemos, R. D., \& Santos, R. D. (1996). Manual de descrição e coleta de solo no campo (Vol. 84). Campinas, Sociedade Brasileira de Ciência do Solo. 
Research, Society and Development, v. 10, n. 2, e10010212130, 2021

(CC BY 4.0) | ISSN 2525-3409 | DOI: http://dx.doi.org/10.33448/rsd-v10i2.12130

Silva, A. H., \& Fossá, M. I. T. (2015). Análise de conteúdo: exemplo de aplicação da técnica para análise de dados qualitativos. Qualitas Revista Eletrônica, 16(1). https://doi.org/10.34117/bjdv6n7-802

Soares, M. D. R., Campos, M. C. C., Oliveira, I. A., Cunha, J. M., Santos, L. A. C., Fonseca, J. S., \& Souza, Z. M. (2016). Atributos físicos do solo em áreas sob diferentes sistemas de usos na região de Manicoré, AM. Revista de Ciências Agrárias Amazonian Journal of Agricultural and Environmental Sciences, 59(1), 9-15. http://dx.doi.org/10.4322/rca.2020

Torres, J. L. R., de Almeida Costa, D. D., da Silva Neto, O. F., Araújo, A. S., Silva, V. R., \& da da Silva Vieira, D. M. (2015). Avaliação da resistência à penetração e densidade do solo num latossolo sob semeadura direta há doze anos-10.14688/1984-3801/gst. v8n1p131-140. Global Science and Technology, 8(1).

Vieira, F. F., Dallacort, R., Barbieri, J. D., Dalchiavon, F. C., \& Daniel, D. F. (2020). Temperatura e umidade do solo em função do uso de cobertura morta no cultivo de milho. Científica, 48(3), 188-199. http://dx.doi.org/10.15361/1984-5529.2020v48n3p188-199 